\title{
Colocación de un balón de oclusión ureteral para el tratamiento de la fístula urinaria posterior a trasplante renal. Reporte de un caso
}

\author{
Placement of a ureteral occlusion balloon catheter for the \\ treatment of urinary fistula after kidney transplantation. A
} case report

\begin{abstract}
Isaac Alejandro Ramírez-Martínez, Roberto Antonio García-Vásquez, Justino López Chente-Casado, Ramiro Vega-Castro, Ariel Vázquez-Gálvez, Ana Laura López-García, Octavio Galeana-Maya, Gabriel López-Acosta, Sergio I. Romero-Reyes
\end{abstract}

\begin{abstract}
Resumen
ANTECEDENTES: La incidencia de fístula urinaria posterior a un trasplante renal varía de 1.2-8.9\%; esta complicación se ha relacionado con necrosis isquémica del uréter. Se recomienda la aplicación de un catéter doble J para disminuir su incidencia.

CASO CLÍNICO: Paciente femenina de 42 años que recibió trasplante renal de donador cadavérico, con reimplante ureterovesical mediante la técnica Lich-Gregoir para anastomosis. Catorce días después del procedimiento inició con salida espontánea de orina por el sitio donde se localizaba el drenaje quirúrgico. El tratamiento inicial consistió en derivación vesical durante cuatro semanas, sin mejoría del cuadro clínico, por lo que se decidió la colocación de un balón de oclusión de $34 \mathrm{Fr}$ x 65 cm (Boston Occluder ${ }^{\circledR}$ ) junto al catéter vesical, además de nefrostomía percutánea. Se logró disminuir el gasto urinario después de una semana y en la tercera se realizó pielografía anterógrada sin evidencia de fuga urinaria; se le retiró el balón de oclusión y se colocó un catéter doble J, con permanencia del catéter de nefrostomía pinzado y la derivación vesical por catéter transuretral. A seis semanas del procedimiento se retiró el catéter ureteral. Luego de 12 meses de seguimiento se observó el cierre completo de la fístula, los volúmenes urinarios y las concentraciones de azoados se encontraron dentro de los parámetros normales, y no se evidenciaron datos de afectación del injerto renal. CONCLUSIONES: La colocación de un balón de oclusión ureteral, además de nefrostomía, representa una nueva alternativa para tratar pacientes con fístula proximal de alto volumen.

PALABRAS CLAVE: Balón de oclusión; fístula urinaria; trasplante renal; tratamiento endoscópico.
\end{abstract}

Abstract

BACKGROUND: The incidence of urinary fistula after kidney transplantation presents in 1.2 to $8.9 \%$ of cases and has been associated with ischemic necrosis of the ureter. Double-J catheter use is recommended to reduce its incidence.

CLINICAL CASE: A 42-year-old woman underwent a deceased-donor kidney transplantation with ureterovesical reimplantation through the Lich-Gregoire technique. Fourteen days after the procedure she presented with spontaneous urine leakage from the site of the surgical drain. Initial management was bladder diversion for four weeks. There was no improvement and so a $34 \mathrm{Fr} \times 65 \mathrm{~cm}$ (Boston Occluder) ureteral occlusion balloon catheter was placed next to the bladder catheter and percutaneous nephrostomy was performed. Reduced urine output was achieved after one week. Antegrade pyelography was carried out at week 3 and showed no urine leakage. The occlusion balloon catheter was removed, and a double-J catheter was placed. The clamped nephrostomy and the bladder diversion through the transurethral catheter remained. The ureteral catheter was removed six weeks after the procedure. After 12 months of follow-up the
Servicio de Urología, Hospital General del Estado de Sonora, Hermosillo.

Recibido: octubre 2017

Aceptado: julio 2018

Correspondencia

Roberto Antonio García Vásquez urologiahge@gmail.com

Este artículo debe citarse como Ramírez-Martínez IA, García-Vásquez RA, López Chente-Casado J, Vega-Castro $R$, Vázquez-Gálvez A, López-García AL, Galeana-Maya O, López-Acosta G, Romero-Reyes SI. Colocación de un balón de oclusión ureteral para el tratamiento de la fístula urinaria posterior a trasplante renal. Reporte de un caso. Rev Mex Urol. 2018 julio-agosto;78(4): 315-320. DOI: https://doi.org/10.24245/revmexurol.v78i4.1691 
fistula was completely closed, urine volume and serum creatinine, serum urea, and blood urea nitrogen levels were within normal parameters. There were no signs of a compromised kidney graft.

CONCLUSIONS: The placement of a ureteral occlusion balloon catheter, in addition to nephrostomy, is a new alternative in the treatment of patients with high-volume proximal fistula.

KEYWORDS: Occlusion balloon; Urinary fistula; Kidney transplantation; Endoscopic treatment.

\section{ANTECEDENTES}

El trasplante renal es la intervención quirúrgica pionera en el trasplante de órganos sólidos. La consolidación de un equipo multidisciplinario ha servido como modelo para establecer el tratamiento médico en la actualidad. ${ }^{1}$ El primer procedimiento quirúrgico exitoso de aloinjerto renal humano fue practicado en Boston, en 1954, y llevado a cabo en gemelos, con supervivencia de ocho años del paciente receptor. ${ }^{2}$

Comparado con la diálisis, el trasplante renal ofrece mayor tasa de supervivencia a 5 años (85.5 vs $38.5 \%$ ), además de mejor calidad de vida y costo-beneficio. ${ }^{3}$ Del primer trasplante renal a la fecha se han mejorado las técnicas quirúrgicas, el uso y la calidad de los aditamentos endourológicos y los equipos endoscópicos, y el avance en el desarrollo de fármacos inmunosupresores han disminuido la incidencia de complicaciones en las últimas décadas en general; sin embargo, las complicaciones urológicas son frecuentes, pueden asociarse con morbilidad significativa $y$, en algunos casos, resultar en pérdida de la función o del injerto. ${ }^{4}$

Las complicaciones urológicas se dividen, según el tiempo de aparición, en tempranas (antes de 90 días del posoperatorio) y tardías (después de 90 días). La fístula urinaria es la complicación urológica temprana más común posterior al trasplante renal, con incidencia de entre 1.2-8.9\% de los casos. ${ }^{5}$ Una de las causas más frecuentes es la necrosis isquémica del uréter, que cuando es pro- ximal puede deberse a necrosis del parénquima por ligadura de arterias polares y cuando es distal puede originarse de la vejiga o del reimplante ureterovesical. En estos casos se recomienda la colocación rutinaria de un catéter doble J para disminuir dicha complicación.

El tratamiento conservador con máximo drenaje mediante la colocación de nefrostomía, catéter ureteral y catéter vesical ha reportado una tasa de éxito de $62 \%$ a 35 meses de seguimiento. ${ }^{6}$ Algunos autores sugieren que los pacientes con fuga de orina proximal o de gran volumen no son ideales para recibir tratamiento conservador; ${ }^{7}$ otros, incluso, proponen que el mejor tratamiento en sujetos con fístula ureteral es la intervención quirúrgica, que no debe reservarse a pacientes en quienes falló el tratamiento endoscópico o percutáneo..$^{8-10}$

Con el advenimiento de los nuevos aditamentos endourológicos, además de los avances en tecnología y equipos médicos, se facilita la aplicación de técnicas de mínima invasión, invitando a innovar en procedimientos que permitan evitar una intervención quirúrgica y, por tanto, ofrecer al paciente procedimientos resolutivos $y$ que provoquen menor daño.

\section{CASO CLÍNICO}

Paciente femenina de 42 años, con insuficiencia renal crónica secundaria a nefropatía diabética, en tratamiento sustitutivo con hemodiálisis. Recibió trasplante renal de donador cadavérico, con 
reimplante ureterovesical, mediante la técnica Lich-Gregoir para anastomosis ureterovesical. Tenía antecedente de lesión advertida del uréter proximal durante la procuración del injerto, reparada antes del reimplante mediante cierre primario con sutura absorbible. Después del trasplante renal tuvo evolución favorable, con adecuada función renal y volúmenes urinarios en los parámetros normales. Se le retiraron los drenajes y se mantuvo con catéter ureteral. Catorce días después inició con salida espontánea de orina por el sitio donde se localizaba el drenaje quirúrgico. El ultrasonido abdominal (Figura 1) evidenció una colección peri-injerto de $130 \mathrm{~mL}$. Se otorgó tratamiento conservador, con derivación mediante catéter vesical, además de la colocación de un catéter ureteral durante 4 semanas; sin embargo, persistió con volúmenes elevados por el sitio de la fístula urinaria, con variación de 800-1500 mL/día, sin datos sugerentes de afectación sistémica.

Puesto que no tuvo reacción satisfactoria con el tratamiento conservador, se decidió utilizar técnicas endourológicas para la complicación posquirúrgica. Siguiendo el principio de drenaje urinario máximo, mediante acceso endoscópico

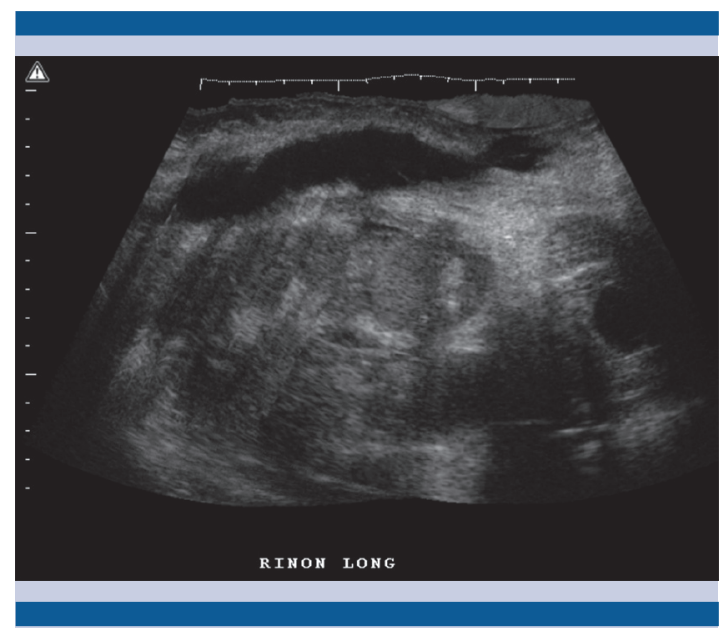

Figura 1. Ultrasonido abdominal que muestra la colección peri-injerto con volumen aproximado de $130 \mathrm{~mL}$.

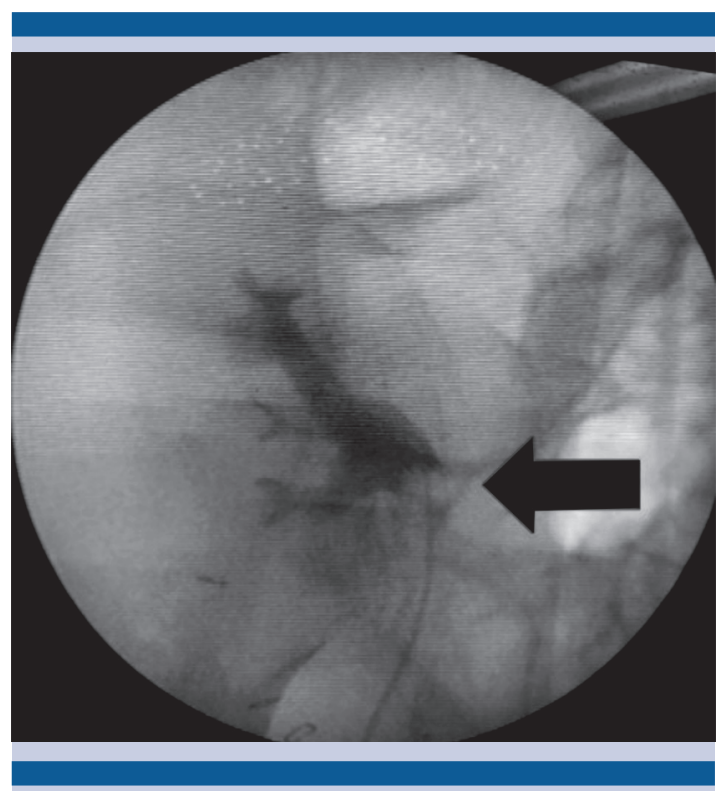

Figura 2. Pielografía retrógrada que evidencian la localización del catéter con balón en la pelvis renal para la oclusión de la unión ureteropiélica.

se colocó un balón de oclusión de 34 Fr x 65 $\mathrm{cm}$ con cubierta de látex (Boston Occluder ${ }^{\circledR}$ ). El procedimiento se llevó a cabo de la siguiente manera: con visión fluoroscópica se aproximó el balón a la unión ureteropiélica (Figura 2) y se infló con la mínima cantidad de solución salina hasta permitir la oclusión del uréter; en este momento el catéter se exteriorizó por la uretra junto con el catéter vesical. De esta manera originó la dilatación de la pelvis renal y posteriormente se colocó un tubo de nefrostomía percutánea para permitir el drenaje urinario, con la finalidad de facilitar el secado y la cicatrización del sitio de la fístula en el uréter.

Luego de una semana se logró disminuir el gasto urinario provocado por la fístula. A la tercera semana se encontró sin gasto y con cierre completo el sitio de la fístula. La pielografía anterógrada (Figura 3) no reportó fuga urinaria, por lo que se retiró el balón de oclusión y se colocó el catéter doble J, con permanencia del catéter de 


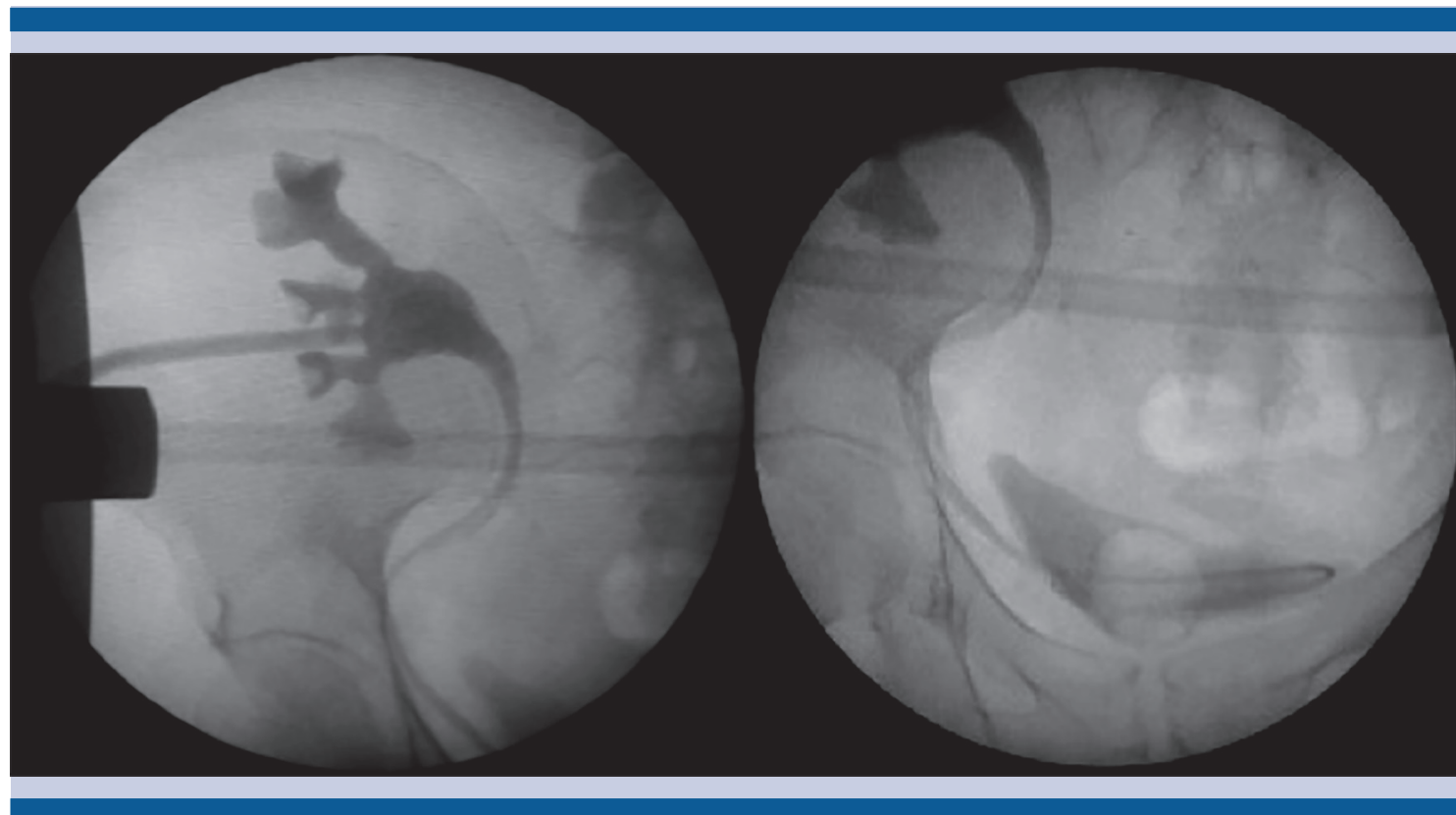

Figura 3. Pielografía retrógrada que muestra la localización del catéter con balón en la pelvis renal para la oclusión de la unión ureteropiélica.

nefrostomía pinzado y la derivación vesical por catéter transuretral. A la cuarta semana se retiró la nefrostomía y seis semanas después el catéter ureteral. Luego de 12 meses de seguimiento se observó el cierre completo de la fístula, los volúmenes urinarios y las concentraciones de azoados se encontraron dentro de los parámetros normales, y no se evidenciaron datos de afectación del injerto renal.

\section{DISCUSIÓN}

Las complicaciones urológicas posteriores al trasplante renal son menos frecuentes en la actualidad y no suelen representar una amenaza para el injerto o la vida del paciente; sin embargo, algunos casos pueden requerir un nuevo procedimiento quirúrgico para su curación completa, lo que aumenta la morbilidad y los costos médicos.
La colocación de un catéter ureteral doble J se indica para disminuir la aparición de fístulas urinarias posterior al trasplante renal; no obstante, algunos estudios han demostrado una tasa de fuga urinaria con y sin la colocación del catéter ureteral de 3.5 y $6.6 \%$, respectivamente. ${ }^{11}$

El tratamiento de referencia de pacientes con fístula urinaria requiere la colocación de un drenaje vesical y un tubo de nefrostomía, además de drenaje de colecciones y medidas de soporte. El tratamiento definitivo en quienes persiste la fístula urinaria consiste en intervención quirúrgica, con reimplantación ureteral y resección del tejido necrótico y del trayecto fistuloso. ${ }^{12}$

El acceso endoscópico es cada vez más frecuente en el tratamiento de las complicaciones urológicas. En pacientes con fístulas urinarias se requiere efectuar el mayor drenaje posible, mediante la colocación del catéter vesical, nefrostomía y 
catéter ureteral. Este tratamiento, que implica el máximo drenaje de orina, ha reportado una tasa de éxito de $69 \%$; sin embargo, disminuye a $58 \%$ por posible origen de estenosis. ${ }^{13}$

Puesto que los pacientes con trasplante renal se encuentran en estado de inmunosupresión y generalmente con alteraciones metabólicas secundarias, considerar el tratamiento de mínima invasión para resolver las complicaciones posquirúrgicas representa la mejor opción, incluso algunos autores lo consideran el tratamiento de primera línea. ${ }^{14}$

El tratamiento implementado en la paciente de este estudio logró mantener seco el uréter y reparar la fístula ureterocutánea proximal de alto volumen en 21 días. Con esto se evitó la reintervención quirúrgica, aumentar la morbilidad y el riesgo de pérdida del injerto.

La colocación de catéteres con balón de oclusión se ha indicado con anterioridad en el tratamiento de pacientes con fístulas secundarias a padecimientos oncológicos. ${ }^{15,16} \mathrm{~A}$ pesar de la experiencia en este tipo de intervenciones, no existe información acerca del tiempo en que un uréter puede ocluirse, pues la posibilidad de necrosis por presión ha limitado la colocación del balón de oclusión a largo plazo. ${ }^{17}$ Günther y su grupo examinaron el uréter de perros después de 3 semanas de oclusión y la histología mostró solamente aplanamiento y una leve reacción inflamatoria del urotelio. ${ }^{15}$ Otros autores no reportan complicaciones con la colocación del catéter con balón de oclusión dentro del uréter durante 94 días, con seguimiento a 12 meses. $^{16}$

\section{CONCLUSIONES}

Aunque las complicaciones urológicas provocadas por el trasplante renal no son frecuentes en la actualidad, pueden afectar la función del injerto y la vida del paciente. La fístula urinaria representa la complicación urinaria temprana más común y suele originarse en el uréter distal, relacionada con necrosis por isquemia. El tratamiento inicial consiste en máxima derivación urinaria; sin embargo, algunos pacientes pueden requerir un nuevo procedimiento quirúrgico como tratamiento definitivo. El acceso endoscópico de mínima invasión es una opción apropiada en casos seleccionados. La colocación de un balón de oclusión ureteral, además de nefrostomía, representa una nueva alternativa en el tratamiento de pacientes con fístula proximal de alto volumen, pues evita efectuar un nuevo procedimiento quirúrgico y ofrece al paciente menor morbilidad y disminución de costos médicos.

\section{REFERENCIAS}

1. Maynard J, Conlin MJ. Urología. 10a ed. Madrid: CampbellWalsh, 2012;2:1244.

2. Murray JE, et al. Renal homotransplantations in identical twins. 1995. J Am Soc Nephrol 2001;12(1):201-4.

3. Purnell TS, et al. Comparison of life participation activities among adults treated by hemodialysis, peritoneal dialysis, and kidney transplantation: a systematic review. DOI: https://doi.org/10.1053/j.ajkd.2013.03.022

4. Krajewski W, et al. Urological complications after renal transplantation: a single centre experience. DOI: 10.5173/ ceju.2016.833

5. Lempinen J, Stenman J, Kyllonen L, Salmela K. Surgical complications following 1670 consecutive adult renal transplantations: a single center study. DOI: https://doi. org/10.1177/1457496914565419

6. Matalon TA, et al. Percutaneous treatment of urine leaks in renal transplantation patients. https://doi.org/10.1148/ radiology.174.3.174-3-1049

7. Duty BD, Barry JM. Diagnosis and management of ureteral complications following renal transplantation. DOI: https:// doi.org/10.1016/j.ajur.2015.08.002

8. Berli JU, et al. Surgical management of early and late ureteral complications after renal transplantation: techniques and outcomes. DOI: https://doi.org/10.1111/ctr.12478

9. Nie ZL, et al. Urological complications in 1,223 kidney transplantations. DOI: https://doi.org/10.1159/000241679

10. Mazzucchi E, et al. Primary reconstruction is a good option in the treatment of urinary fistula after kidney transplantation. International Braz J Urol 2006;32(4):398-404. 
11. Dominguez J, et al., Is routine ureteric stenting needed in kidney transplantation? A randomized trial. Transplantation 2000;70(4):597-601.

12. Van Roijen $\mathrm{JH}$, et al. Long-term graft survival after urological complications of 695 kidney transplantations. J Urol 2001;165:1884-7.

13. Fonio $\mathrm{P}$, et al. Treatment of urological complications in more than 1,000 kidney transplantations: the role of interventional radiology. DOI: 10.1007/s11547-014-0407-y
14. Duty D, et al. The current role of endourologic management of renal transplantation complications. DOI: http://dx.doi. org/10.1155/2013/246520

15. Günther RW, et al. Transrenal ureteral occlusion using a detachable balloon. Urol Radiol 1984;6:210-214.

16. Horenblas SA, et al. Use of Balloon Catheters for Ureteral Occlusion in Urinary Leakage. DOI: https://doi. org/10.1159/000020340

17. Moldwin RM, Smith AD. Percutaneous management of ureteral fistulas. Urol Clin North Am 1988;15:3.

\section{AVISO IMPORTANTE}

La Revista Mexicana de Urología se convierte en una publicación solo digital, con todas las ventajas que los medios y dispositivos electrónicos ofrecen. Usted podrá revisar la información mediante el sitio web (www.revistamexicanadeurologia.org.mx) o descargando la app para Android o iPhone.

Para consultar el texto completo de los artículos deberá registrarse por una sola vez con su correo electrónico, crear una contraseña, indicar su nombre, apellidos y especialidad.

Esta información es indispensable para saber qué consulta y cuáles son sus intereses, y poder en el futuro inmediato satisfacer sus necesidades de información. 